\title{
ATRIBUTOS QUÍMICOS DO SOLO E PRODUTIVIDADE DE VIDEIRAS ALTERADOS PELO MANEJO DE COBERTURAS VERDES NA SERRA GAÚCHA ${ }^{(1)}$
}

\author{
Jaqueline Dalla Rosa ${ }^{(2)}$, Álvaro Luiz Mafra ${ }^{(3)}$, Marcos André Nohatto( ${ }^{(4)}$, \\ Evandro Zacca Ferreira $^{(4)}$, Odoni Loris Pereira de Oliveira ${ }^{(5)}$, David José \\ Miquelluti $^{(3)}$, Paulo Cezar Cassol ${ }^{(3)}$ \& João Carlos Medeiros ${ }^{(2)}$
}

\begin{abstract}
RESUMO
O manejo do solo pode interferir na disponibilidade de nutrientes e na produtividade de frutos. O objetivo deste estudo foi avaliar o efeito de formas de manejo da fitomassa de diferentes espécies de plantas de cobertura verde sobre características químicas do solo, relacionadas à matéria orgânica e à disponibilidade de nutrientes, e sobre a produtividade de uva. $O$ experimento foi realizado na Embrapa Uva e Vinho, em Bento Gonçalves, RS, sobre um Cambissolo Háplico, num parreiral implantado em 1989, com os cultivares Niágara Branca e Niágara Rosada, no sistema de latada. Os tratamentos testados foram implantados em 2002 e consistiram em três coberturas vegetais: vegetação espontânea, aveiapreta e consórcio de trevo-branco + trevo-vermelho + azevém; e dois sistemas de manejo: dessecado com herbicida e roçado, os quais foram realizados no outono, previamente à ressemeadura das espécies. O delineamento experimental foi de blocos ao acaso com três repetições. Os atributos químicos indicadores da acidez e da disponibilidade de nutrientes no solo foram pouco influenciados pelas espécies de cobertura. A dessecação das plantas aumentou os teores de Ca e Mg trocáveis, $P$ disponível e $\mathbf{C}$ orgânico total em relação ao manejo roçado. A produtividade de uva nas safras de 2004 e 2006 foi baixa em relação ao potencial dos cultivares, possivelmente por restrições climáticas, contudo foi maior quando se utilizou a aveia como planta de cobertura do que com o consórcio de plantas.
\end{abstract}

Termos de indexação: adubo verde, manejo do solo, nutrientes, plantas de cobertura, Vitis labrusca.

(1) Parte da Dissertação de Mestrado em Manejo do Solo do primeiro autor, na Universidade do Estado de Santa Catarina UDESC. Recebido para publicação em julho de 2008 e aprovado em novembro de 2008.

(2) Doutorando em Solos e Nutrição de Plantas, Escola Superior de Agricultura "Luiz de Queiroz" - ESALQ/USP. Av. Pádua Dias 11, CEP 13418-900 Piracicaba (SP). E-mail: jaqueline.dr@gmail.com

(3) Professor Adjunto do Departamento de Solos e Recursos Naturais, Universidade do Estado de Santa Catarina - UDESC. Caixa Postal 281, CEP 88520-000 Lages (SC). E-mail: a2alm@cav.udesc.br

(4) Acadêmico do Curso de Agronomia, CAV/UDESC. Bolsista de Iniciação Científica do CNPq. E-mail: marcosnohatto@ig.com.br

(5) Pesquisador aposentado da Embrapa Uva e Vinho. Centro Nacional de Pesquisa Uva e Vinho - CNPUV. Caixa postal 130, CEP 95700-000 Bento Gonçalves (RS). E-mail: odoni.l@terra.com.br 


\title{
SUMMARY: SOIL CHEMICAL PROPERTIES AND GRAPEVINE YIELD AFFECTED BY COVER CROP MANAGEMENT IN SERRA GAUCHA, SOUTHERN BRAZIL
}

\begin{abstract}
Soil management can have effects on nutrient availability and fruit yield. The objective of this study was to evaluate the effect of phytomass management forms of different cover crop species on soil chemical properties related to organic matter, nutrient availability, and on grapevine yields. The experiment was carried out in Embrapa Uva e Vinho, in Bento Gonçalves, RS, in Southern Brazil, on a Haplic Cambissol, in a vineyard established in 1989, using White and Rose Niagara grape in a horizontal overhead trelling system. The treatments established in 2002 were three cover crops: spontaneous native species, black oat (Avena strigosa), and a mixture of white clover (Trifolium repens) + red clover (Trifolium pratense) + annual ryegrass (Lolium multiflorum); and two management systems: desiccation by herbicide spraying and mechanical mowing, performed each autumn prior to cover crop resowing. The experiment had a completely randomized block design, with three replications. Soil acidity and nutrient contents were little influenced by the plant cover. In comparison with the mowed management, herbicide application increased exchangeable $\mathrm{Ca}$ and $\mathrm{Mg}$, extracted $\mathrm{P}$, and organic C levels in the soil. The grape yield in the seasons 2004 and 2006 was low in view to the cultivar potential, probably affect by climatic limitations, but was higher when black oat was used as plant cover instead of the mixture of plant covers.
\end{abstract}

Index terms: cover crops, green manure, nutrients, soil management, Vitis labrusca.

\section{INTRODUÇÃO}

A videira é tradicionalmente cultivada no sul do Brasil, sendo a Serra Gaúcha, situada na encosta nordeste do Estado do Rio Grande do Sul, a maior região vitivinícola do País. Este cultivo ocorre, predominantemente, em pequenas propriedades, onde os parreirais são estabelecidos em áreas declivosas, com solos rasos e pedregosos, sujeitos à degradação, especialmente no sistema de cultivo tradicional, em que o terreno é mantido descoberto (Oliveira et al., 2004). Nessa situação, as alterações no solo podem interferir negativamente no desenvolvimento da videira, com consequente diminuição da produção (Klik et al., 1998).

Assim, a manutenção de características físicas, químicas e biológicas dos solos favoráveis ao cultivo de videiras, considerando-se ainda aspectos nutricionais relacionados à qualidade e produtividade, são demandas prioritárias nesta região (Protas, 2005). A cobertura verde representa uma alternativa conservacionista a ser utilizada nos parreirais, pois diminui as perdas de solo e nutrientes por erosão (Battany \& Grismer, 2000). A utilização de espécies de cobertura que protejam e recuperem a fertilidade dos solos é importante para manter sua capacidade produtiva, tanto quantitativa quanto qualitativamente (Tesic et al., 2007).

Porém, o manejo da vegetação de cobertura deve ser adequado para evitar competição com a videira, diminuindo a produção de uva. Os períodos mais críticos de competição ocorrem durante as fases de brotação, na primavera e de pós-colheita da uva que, dependendo do cultivar, pode ser de meados do verão até início do outono, quando ainda há formação e estoque de reservas nutritivas para o próximo ciclo (Oliveira et al., 2007).

Em áreas declivosas, a cobertura vegetal é fundamental para reduzir o processo erosivo no solo, diminuindo o escoamento superficial, perdas de água, solo e nutrientes, como verificado num parreiral em solo com impedimento da infiltração de água devido ao selamento superficial (Louw \& Bennie, 1992). Outro aspecto ligado à cobertura vegetal é o incremento da ciclagem de nutrientes, o que reduz a lixiviação, pois os elementos absorvidos são incorporados à fitomassa e retornam ao solo com a decomposição das plantas. Além disso, a cobertura vegetal aumenta a quantidade de matéria orgânica do solo e diminui a lixiviação de nitratos em relação ao terreno descoberto e arado (Giovannini et al., 2003). Leguminosas utilizadas como adubação verde em parreiral podem melhorar as características químicas do solo, aumentando os teores de matéria orgânica e cálcio trocável, e a CTC na camada de 0 a $10 \mathrm{~cm}$ de profundidade, porém sem alterar a produtividade e qualidade da uva (Faria et al., 2004).

A cobertura morta obtida com a roçada ou o dessecamento de plantas espontâneas, comumente denominada capim, que é tradicionalmente utilizada nas ruas de parreirais na Serra Gaúcha, pode ser substituída pelo cultivo intercalado de espécies como aveia-preta, sem comprometer a qualidade dos frutos da videira Niágara Rosada (Wutke et al., 2004). O manejo da aveia-preta mediante roçada na primavera, em substituição a invasoras dessecadas, também não influenciou a produtividade de uva do cultivar Isabel (Rombaldi et al., 2004). 
Assim, este trabalho tem por objetivo avaliar a influência de diferentes coberturas verdes e formas de manejo da fitomassa sobre características químicas do solo, relacionadas à matéria orgânica, à disponibilidade de nutrientes e à produtividade de uva em parreiral da Serra Gaúcha.

\section{MATERIAL E MÉTODOS}

O estudo foi realizado em Bento Gonçalves, RS, em área experimental pertencente à Embrapa Uva e Vinho, com altitude de $680 \mathrm{~m}$. O clima da região é mesotérmico úmido, tipo Cfb segundo a classificação de Köppen, com temperatura média anual de $17,6^{\circ} \mathrm{C}$ e precipitação anual de $1.793 \mathrm{~mm}$, bem distribuída ao longo do ano (Falcade \& Mandelli, 1999).

O parreiral foi implantado em 1989, sobre um Cambissolo Háplico eutrófico derivado de basalto, utilizando-se Vitis labrusca (L.) dos cultivares Niágara Branca e Niágara Rosada, no espaçamento de 1,5 m entre plantas e $2,5 \mathrm{~m}$ entre fileiras, realizado no sistema de latada. Na implantação do parreiral, foram feitas adubação e calagem com base em análise prévia do solo, conforme indicações da Comissão de Fertilidade do Solo (CFSRS/SC, 1989).

Os tratamentos foram aplicados em três safras, sempre nas mesmas parcelas, a partir de 2002, quando se iniciou a adoção das espécies de cobertura do solo no parreiral. Nessa ocasião, realizou-se análise de solo, tendo-se observado teores de nutrientes acima dos níveis considerados críticos para o desenvolvimento das plantas de cobertura, dispensando-se calagem e adubação durante o período de avaliação. Os tratamentos aplicados foram três coberturas vegetais: vegetação espontânea (VE) com predomínio de gramamissioneira (Axonopus spp.), grama-forquilha (Paspalum notatum Fluggé) e grama-bermuda (Cynodon dactilon (L.) Pers.); aveia-preta (Avena strigosa Schreb) (A); e consórcio de trevo-branco (Trifolium repens L.) + trevo-vermelho (Trifolium pratense L.) + azevém (Lolium multiflorum Lam) (C); e duas formas de manejo: convencional (D) e roçado (R). O manejo convencional foi constituído pela dessecação por herbicida, e o roçado foi corte com roçadeira mecânica giratória. As parcelas abrangeram três linhas de quatro plantas, mantendo-se uma linha adicional de plantas como bordadura. Esses tratamentos foram distribuídos em arranjo fatorial completo $3 \times 2$, sendo dispostos em delineamento experimental de blocos ao acaso, com três repetições.

A semeadura das plantas de cobertura foi feita a lanço e sem incorporação das sementes, de forma uniforme na linha e entrelinha, empregando-se $100 \mathrm{~kg} \mathrm{ha}^{-1}$ de sementes para aveia e, para o consórcio, $25 \mathrm{~kg} \mathrm{ha}^{-1}$ de azevém, 3,0 $\mathrm{kg} \mathrm{ha}^{-1}$ de trevo-branco e $6,0 \mathrm{~kg} \mathrm{ha}^{-1}$ de trevo-vermelho. Somente a aveia recebeu ressemeadura anual, visto que as demais espécies perenizaram. O manejo da vegetação foi realizado uma única vez em cada ano, na primeira metade do mês de abril, de forma uniforme nas linhas e entrelinhas. No manejo convencional, utilizaramse 4,0 L ha ${ }^{-1}$ de herbicida sistêmico Glyfosato e, 15 dias depois, foi efetuado o manejo com roçadora de facas giratórias acoplada ao trator.

A produção de matéria seca das plantas de cobertura foi determinada em 15 de setembro de 2003 , 2004 e 2005. As amostras foram retiradas em um quadrado de 0,50 x 0,50 m, cortando-se o material vegetal rente ao solo, coletando-se três subamostras por parcela localizada nas entrelinhas. Esta fitomassa foi seca em estufa a $65^{\circ} \mathrm{C}$ até atingir massa constante.

A amostragem do solo foi realizada em março de 2006, nas profundidades de 0-5 e 5-10 cm, nas linhas e entrelinhas do parreiral, coletando-se em cada parcela uma amostra composta originada de seis subamostras. Foi também amostrada uma área com mata nativa (MN), adjacente à área experimental, representando a condição original do solo. Foram determinados os atributos de solo: C orgânico, analisado pelo método de oxidação úmida; Ca e Mg trocáveis, extraídos com solução neutra de $\mathrm{KCl} 1 \mathrm{~mol} \mathrm{~L}^{-1}$ e quantificados por espectrofotometria de absorção atômica; Al trocável, quantificado por titulometria de neutralização; P e K disponíveis extraídos com solução ácida (Mehlich-1), sendo o $\mathrm{P}$ quantificado por colorimetria e $\mathrm{K}$ por fotometria de chama. $\mathrm{O} \mathrm{pH}$ foi determinado na relação $1: 1$, de solo com água e com solução de $\mathrm{CaCl}_{2}$ 0,01 $\mathrm{mol} \mathrm{L}^{-1}$, com leitura em potenciômetro (Tedesco et al., 1995).

$\mathrm{Na}$ implantação do experimento, em 2002, identificaram-se aleatoriamente quatro plantas que foram colhidas para determinação da produtividade em cada safra. A produção de uva nas safras de 2004 a 2006 foi avaliada nessas quatro plantas por parcela, colhendo-se todos os cachos de forma a obter a massa de frutos frescos por planta.

A análise estatística foi realizada considerando grupos de experimentos, fixando-se profundidade e posição de amostragem para os atributos do solo e avaliando-se os efeitos das coberturas e do manejo da vegetação. Os tipos de manejo foram considerados como efeito fixo, e foram testadas coberturas, manejo, e interação cobertura x manejo como efeitos aleatórios. Para avaliação da produtividade de uva foi fixado o fator época, não sendo analisada a interação ano x tratamento. Foi realizada análise de variância multivariada e, nos casos em que esta foi significativa, procedeu-se à análise univariada, utilizando contrastes para comparação das médias $(\mathrm{p}<0,05)$. Para a mata nativa, calculou-se o intervalo de confiança pelo teste t.

\section{RESULTADOS E DISCUSSÃO}

A produção de matéria seca (MS) das plantas de cobertura em 2003 variou de 3.800 a $6.350 \mathrm{~kg} \mathrm{ha}^{-1}$ 
Quadro 1. Produção de matéria seca de plantas de cobertura do solo em parreiral em dois sistemas de manejo, colhidas em setembro, em três anos consecutivos, e análise de contrastes entre tratamentos, Bento Gonçalves, RS

\begin{tabular}{|c|c|c|c|}
\hline Cobertura-manejo/contrastes & 2003 & 2004 & 2005 \\
\hline & \multicolumn{3}{|c|}{$\mathrm{kg} \mathrm{ha} \mathrm{a}^{-1}$} \\
\hline Vegetação espontânea dessecada (VE D) & 3.900 & 2.750 & 2.050 \\
\hline Aveia-preta dessecada (A D) & 5.300 & 3.100 & 2.850 \\
\hline Consórcio $^{(1)}$ dessecado (C D) & 3.800 & 3.950 & 2.850 \\
\hline Vegetação espontânea roçada (VE R) & 4.550 & 4.350 & 2.550 \\
\hline Aveia-preta roçada (A R) & 6.350 & 3.300 & 2.650 \\
\hline Consórcio roçado (C R) & 3.800 & 3.200 & 2.400 \\
\hline $\mathrm{VE}$ us A,C & ns & ns & $*$ \\
\hline $\mathrm{VE}$ us $\mathrm{A}$ & $*$ & ns & $*$ \\
\hline $\mathrm{A}$ vs C & * & ns & ns \\
\hline VE vs C & $\mathrm{ns}$ & $\mathrm{ns}$ & $*$ \\
\hline $\mathrm{C} \mathrm{D}$ us $\mathrm{C} \mathrm{R}$ & ns & $\mathrm{ns}$ & * \\
\hline VE $\mathrm{D}$ vs VE R & ns & * & * \\
\hline
\end{tabular}

(1) Consórcio de trevo-branco, trevo-vermelho e azevém; * significativo a 5 \%, ns: não-significativo.

(Quadro 1), sendo a aveia-preta a mais produtiva, em relação às demais. Em 2004, as plantas de cobertura produziram de 2.750 a $4.350 \mathrm{~kg} \mathrm{ha}^{-1}$, tendo-se observado diferença somente na vegetação espontânea, onde houve maior produção no manejo roçado em relação ao dessecado. Já em 2005, as plantas de cobertura produziram apenas de 2.050 a $2.850 \mathrm{~kg} \mathrm{ha}^{-1}$ de MS, porém nesta safra foram observadas maiores diferenças entre coberturas e manejos (Quadro 1).

A produção de fitomassa das espécies de cobertura no período de avaliação pode ter sido influenciada por competição por água, nutrientes, ou sombreamento promovido pelas videiras. Além disso, pode ter havido alelopatia negativa entre as plantas, em virtude do cultivo sucessivo, que pode ter influenciado na germinação de sementes de ressemeadura natural e reduzido o desenvolvimento vegetativo. Resultado semelhante foi observado por Faria et al. (2004), que constataram decréscimo na produção de matéria seca de espécies leguminosas de cobertura implantadas num parreiral em Petrolina, PE, ao longo de onze ciclos, de 3.000 para $1.000 \mathrm{~kg} \mathrm{ha}^{-1}$ no feijão-de-porco (Canavalia ensiformis (L.) DC.) e de 6.000 para $2.500 \mathrm{~kg} \mathrm{ha}^{-1}$ na crotalária (Crotalaria juncea L.).

É previsível que a produção de fitomassa das plantas de cobertura no interior do parreiral seja menor do que em cultivo solteiro, devido principalmente ao efeito de sombreamento proporcionado pelas videiras. Variação na produção de fitomassa entre espécies de cobertura também foi observada por Rufato et al. (2007), que, em pomares de pessegueiro, em Morro Redondo, RS, constataram, ao final do segundo ciclo desde a implantação das espécies, produção de matéria seca de $2.600 \mathrm{~kg} \mathrm{ha}^{-1}$ para aveia-preta em cultivo solteiro, e $5.000 \mathrm{~kg} \mathrm{ha}{ }^{-1}$ para a mistura de aveia-preta e chícharo (Lathyrus sativus L.).

A avaliação da acidez do solo (Quadro 2) no parreiral evidenciou solos ligeiramente ácidos com teores de $\mathrm{Al}$ trocável, que variaram de 0,03 a $0,07 \mathrm{cmol}_{\mathrm{c}} \mathrm{dm}^{-3}$. Estes valores notadamente baixos provavelmente retratam a acidez trocável devida ao $\mathrm{H}^{+}$adsorvido às cargas negativas do solo, pois o $\mathrm{pH}$ em água se situou acima de 5,7 em todas as parcelas, o que torna improvável a existência de $\mathrm{Al}^{3+}$ no solo. $\mathrm{O} \mathrm{pH}$ em água variou de 5,7 a 5,9, sem efeito das coberturas e dos sistemas de manejo (Quadro 2). Na mata nativa, o pH em água foi 4,7, o que indica a condição de acidez natural deste solo, também constatada pela presença de Al trocável, com teor de $1,2 \mathrm{cmol}_{\mathrm{c}} \mathrm{dm}^{-3}$. $\mathrm{O} \mathrm{pH}$ em solução salina variou de 5,1 a 5,5 na área do parreiral, e foi de 4,0 na mata. Na camada de 0 a $5 \mathrm{~cm}$, este atributo foi superior na vegetação espontânea em relação às demais espécies, tanto na linha quanto na entrelinha, o que não ocorreu para o pH em água. Este resultado indica que o pH em solução salina é um atributo sensível a efeitos de baixa magnitude, geralmente associados à ação de plantas no $\mathrm{pH}$ do solo (Pocknee \& Sumner, 1997).

Os teores de $\mathrm{K}$ no solo variaram de 181 a $288 \mathrm{mg} \mathrm{dm}^{-3}$, porém não se observou efeito dos tratamentos (Quadro 3). Entretanto, no parreiral, os valores foram superiores ao observado na mata nativa, $103 \mathrm{mg} \mathrm{dm}^{-3}$, diferença que mostra o efeito positivo da adubação realizada na cultura. Os teores de Ca variaram de 7,2 a 11,2 $\mathrm{cmol}_{\mathrm{c}} \mathrm{dm}^{-3}$ no solo sob parreiral, também diferindo daqueles da mata nativa, que apresentou $1,03 \mathrm{cmol}_{\mathrm{c}} \mathrm{dm}^{-3}$, o que é explicado principalmente pela incorporação e retenção no solo 
Quadro 2. Atributos relacionados à acidez em duas camadas do solo, na linha e entrelinha de plantas de um parreiral em Cambissolo Háplico eutrófico, sob diferentes plantas de cobertura, em dois sistemas de manejo e em mata nativa de área adjacente, e análise de contrastes entre tratamentos. Bento Gonçalves, RS

\begin{tabular}{|c|c|c|c|c|c|c|}
\hline \multirow[t]{5}{*}{ Cobertura/contrastes } & \multicolumn{2}{|c|}{ pH água } & \multicolumn{2}{|c|}{$\mathrm{pH} \mathrm{CaCl}{ }_{2}$} & \multicolumn{2}{|c|}{$\mathrm{Al}\left(\mathrm{cmol}_{\mathrm{c}} \mathbf{d m}^{-3}\right)$} \\
\hline & \multicolumn{6}{|c|}{ Mata nativa: $0-10 \mathrm{~cm}$} \\
\hline & \multicolumn{2}{|c|}{$4,7 \pm 0,3$} & \multicolumn{2}{|c|}{$4,0 \pm 0,3$} & \multicolumn{2}{|c|}{$1,2 \pm 0,2$} \\
\hline & \multicolumn{6}{|c|}{ Profundidade: $0-5 \mathrm{~cm}$} \\
\hline & Linha & Entrelinha & Linha & Entrelinha & Linha & Entrelinha \\
\hline Vegetação espontânea (VE) & 5,8 & 5,8 & 5,4 & 5,3 & 0,03 & 0,04 \\
\hline Aveia-preta (A) & 5,7 & 5,7 & 5,3 & 5,2 & 0,06 & 0,06 \\
\hline Consórcio $^{(1)}$ (C) & 5,7 & 5,7 & 5,3 & 5,2 & 0,05 & 0,05 \\
\hline \multirow[t]{2}{*}{$\mathrm{VE}$ vs $(\mathrm{A}, \mathrm{C})$} & ns & ns & $*$ & $*$ & ns & $*$ \\
\hline & \multicolumn{6}{|c|}{ Profundidade: $5-10 \mathrm{~cm}$} \\
\hline Vegetação espontânea (VE) & 5,9 & 5,9 & 5,4 & 5,2 & 0,04 & 0,06 \\
\hline Aveia-preta (A) & 5,8 & 5,9 & 5,2 & 5,2 & 0,07 & 0,07 \\
\hline 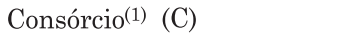 & 5,7 & 5,8 & 5,1 & 5,2 & 0,07 & 0,07 \\
\hline $\mathrm{VE}$ vs $(\mathrm{A}, \mathrm{C})$ & ns & $\mathrm{ns}$ & ns & $\mathrm{ns}$ & * & ns \\
\hline
\end{tabular}

(1) Consórcio de trevo-branco, trevo-vermelho e azevém; $\mathrm{pH}$ água: $\mathrm{pH}$ determinado em água; $\mathrm{pH} \mathrm{CaCl}_{2}: \mathrm{pH}$ determinado em solução de $\mathrm{CaCl}_{2}$ 0,01 mol L'-1; Al: Alumínio trocável; *: significativo a $5 \%$; ns: não-significativo. Os valores da mata nativa referem-se à média das profundidades, e são acompanhados do intervalo de confiança, calculado pelo teste t. Na tabela, são apresentados somente os contrastes significativos.

do elemento com a calagem realizada na implantação do parreiral. Houve interação entre sistema de manejo e plantas de cobertura na camada superficial da entrelinha, observando-se maior teor de $\mathrm{Ca}$ na vegetação espontânea e na aveia dessecadas do que no manejo dessas coberturas roçadas (Quadro 3). Faria et al. (2004), utilizando adubação verde com leguminosas em parreirais de Petrolina-PE, sob um Argissolo Amarelo, após oito anos, observaram diversas melhorias nas características químicas do solo, incluindo aumento nos teores de Ca trocável na camada de $0-10 \mathrm{~cm}$ de profundidade em relação à testemunha, sem adubação verde. Silva et al. (2002), também observaram aumento nos teores de Ca, após a implantação de espécies leguminosas intercalares em pomar de laranja-pera, comparativamente à situação do solo antes do experimento.

$\mathrm{O}$ teor de $\mathrm{Mg}$ trocável observado na mata nativa foi $0,7 \mathrm{cmol}_{\mathrm{c}} \mathrm{dm}^{-3}$, também inferior aos teores observados no solo do parreiral, que se situou entre 1,7 e 3,0 $\mathrm{cmol}_{\mathrm{c}} \mathrm{dm}^{-3}$ (Quadro 3), com variações entre os tratamentos. Na camada superficial da linha de plantio, foram observados efeitos das plantas de cobertura e dos manejos da biomassa. Os maiores teores de $\mathrm{Mg}$ foram observados na vegetação espontânea, e os menores na aveia. Já em relação aos sistemas de manejo, os maiores teores de $\mathrm{Mg}$ no solo foram observados no tratamento dessecado, em relação ao roçado, independente da planta de cobertura, indicando maior contribuição da cobertura manejada quimicamente na ciclagem deste nutriente. Esse efeito se repetiu na camada de 5 a $10 \mathrm{~cm}$.

Os teores de $\mathrm{P}$ disponível variaram de 26 a $73 \mathrm{mg} \mathrm{dm}^{-3}$ (Quadro 3), sendo acentuadamente superiores ao observado no solo de mata nativa, que apresentou $0,3 \mathrm{mg} \mathrm{dm}^{-3}$, o que evidencia o incremento da disponibilidade deste elemento decorrente da adubação realizada na implantação do parreiral. $\mathrm{Na}$ camada de $0-5 \mathrm{~cm}$ da linha de plantio das videiras, houve interação entre sistema de manejo e planta de cobertura, onde a vegetação espontânea dessecada apresentou maiores teores de $\mathrm{P}$ quando comparada à aveia e ao consórcio dessecados. Já no manejo roçado, observou-se maior teor de $\mathrm{P}$ na aveia do que no consórcio. O efeito de manejo também foi significativo para a vegetação espontânea e o consórcio, tendo-se observado maior teor de $\mathrm{P}$ no manejo dessecado do que no roçado.

Na camada de 5-10 cm do solo da linha de plantio, os maiores teores de $\mathrm{P}$ disponível foram observados na vegetação espontânea quando comparada à aveia $\mathrm{e}$ ao consórcio, porém não se detectou efeito do manejo nesta camada (Quadro 3). Já na entrelinha, ocorreu efeito significativo de manejo nas três coberturas, com maior concentração de $\mathrm{P}$ disponível no manejo dessecado em relação ao roçado. Este resultado, também observado para $\mathrm{Ca}^{2+}$ e $\mathrm{Mg}^{2+}$, pode ser explicado pela maior liberação desses nutrientes a partir das plantas dessecadas, devido à sua 
Quadro 3. Teores de Ca e Mg trocáveis, K e P extraíveis (Mehlich) e C orgânico em duas camadas do solo, na linha e entrelinha de plantas de um parreiral em Cambissolo Háplico eutrófico, sob diferentes plantas de cobertura, em dois sistemas de manejo e em mata nativa de área adjacente, e análise de contrastes entre tratamentos. Bento Gonçalves, RS

\begin{tabular}{|c|c|c|c|c|c|c|c|c|c|c|}
\hline \multirow[t]{6}{*}{ Cobertura-manejo/contrastes } & \multicolumn{2}{|c|}{$\mathbf{K}$} & \multicolumn{2}{|c|}{$\mathrm{Ca}^{2+}$} & \multicolumn{2}{|c|}{$\mathrm{Mg}^{2+}$} & \multicolumn{2}{|c|}{$\mathbf{P}$} & \multicolumn{2}{|c|}{$\mathrm{CO}$} \\
\hline & \multicolumn{2}{|c|}{$\mathrm{mg} \mathrm{dm} \mathrm{m}^{-3}$} & \multirow{2}{*}{\multicolumn{4}{|c|}{ 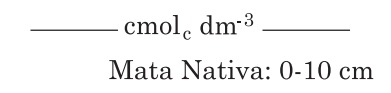 }} & \multicolumn{2}{|c|}{$\mathrm{mg} \mathrm{dm} \mathrm{dm}^{-3}$} & \multicolumn{2}{|c|}{$\mathrm{g} \mathrm{kg}^{-1}$} \\
\hline & & & & & & & & & & \\
\hline & \multicolumn{2}{|c|}{$103 \pm 11,3$} & \multicolumn{2}{|c|}{$1,03 \pm 0,3$} & \multicolumn{2}{|c|}{$0,7 \pm 0,4$} & \multicolumn{2}{|c|}{$0,3 \pm 0,1$} & \multicolumn{2}{|c|}{$26 \pm 7$} \\
\hline & \multicolumn{8}{|c|}{ Profundidade: $0-5 \mathrm{~cm}$} & \multirow{2}{*}{\multicolumn{2}{|c|}{ L EL }} \\
\hline & $\mathrm{L}$ & EL & $\mathrm{L}$ & EL & $\mathrm{L}$ & $\mathrm{EL}$ & $\mathrm{L}$ & $\mathrm{EL}$ & & \\
\hline Veget. espon. $(\mathrm{VE})^{(1)} \mathrm{D}^{(2)}$ & 208 & 216 & 11,2 & 9,6 & 3,0 & 2,5 & 73 & 65 & 32 & 31 \\
\hline Aveia-preta D & 216 & 288 & 10,2 & 9,5 & 2,6 & 2,4 & 54 & 74 & 36 & 31 \\
\hline Consórcio $^{(3)} \mathrm{D}$ & 288 & 197 & 9,8 & 9,5 & 2,8 & 2,7 & 60 & 63 & 34 & 29 \\
\hline Veget. espon. $R^{(4)}$ & 197 & 199 & 9,4 & 9,2 & 2,5 & 1,9 & 49 & 51 & 28 & 28 \\
\hline Aveia-preta R & 199 & 219 & 8,6 & 9,3 & 2,2 & 2,1 & 56 & 68 & 30 & 28 \\
\hline Consórcio R & 219 & 210 & 9,4 & 9,4 & 2,4 & 1,8 & 39 & 56 & 34 & 30 \\
\hline VED vs (AD,CD) & $\mathrm{ns}$ & $\mathrm{ns}$ & $\mathrm{ns}$ & $\mathrm{ns}$ & $\mathrm{ns}$ & $\mathrm{ns}$ & * & $\mathrm{ns}$ & $\mathrm{ns}$ & $\mathrm{ns}$ \\
\hline $\mathrm{AR}$ vs $\mathrm{CR}$ & ns & $\mathrm{ns}$ & $\mathrm{ns}$ & ns & ns & $\mathrm{ns}$ & * & $\mathrm{ns}$ & $\mathrm{ns}$ & * \\
\hline $\mathrm{VE}$ us $(\mathrm{A}, \mathrm{C})$ & $\mathrm{ns}$ & $\mathrm{ns}$ & $\mathrm{ns}$ & $\mathrm{ns}$ & * & $\mathrm{ns}$ & $\mathrm{ns}$ & $\mathrm{ns}$ & $\mathrm{ns}$ & $\mathrm{ns}$ \\
\hline $\mathrm{A}$ vs $\mathrm{C}$ & $\mathrm{ns}$ & $\mathrm{ns}$ & $\mathrm{ns}$ & $\mathrm{ns}$ & * & $\mathrm{ns}$ & ns & ns & ns & ns \\
\hline VED vs VER & $\mathrm{ns}$ & $\mathrm{ns}$ & $\mathrm{ns}$ & * & * & $\mathrm{ns}$ & * & $\mathrm{ns}$ & $\mathrm{ns}$ & * \\
\hline $\mathrm{AD}$ vs $\mathrm{AR}$ & ns & ns & ns & * & * & $\mathrm{ns}$ & ns & $\mathrm{ns}$ & ns & ns \\
\hline \multirow[t]{2}{*}{$\mathrm{CD}$ us $\mathrm{CR}$} & $\mathrm{ns}$ & $\mathrm{ns}$ & $\mathrm{ns}$ & ns & * & $\mathrm{ns}$ & $*$ & $\mathrm{~ns}$ & $\mathrm{~ns}$ & $\mathrm{~ns}$ \\
\hline & \multicolumn{8}{|c|}{ Profundidade: $5-10 \mathrm{~cm}$} & & \\
\hline Veget. espon. D & 288 & 197 & 10,8 & 9,3 & 2,9 & 2,8 & 38 & 46 & 24 & 19 \\
\hline Aveia-preta D & 197 & 199 & 9,3 & 9,2 & 2,7 & 2,4 & 35 & 45 & 21 & 21 \\
\hline Consórcio D & 199 & 219 & 7,4 & 8,6 & 2,3 & 2,6 & 27 & 46 & 24 & 18 \\
\hline Veget. espon. R & 219 & 210 & 8,4 & 9,7 & 2,1 & 2,0 & 55 & 34 & 15 & 18 \\
\hline Aveia-preta R & 210 & 181 & 7,2 & 8,9 & 1,9 & 2,0 & 30 & 40 & 21 & 21 \\
\hline Consórcio R & 181 & 203 & 8,2 & 8,8 & 2,1 & 1,7 & 26 & 34 & 23 & 21 \\
\hline $\mathrm{VE} v s(\mathrm{~A}, \mathrm{C})$ & $\mathrm{ns}$ & $\mathrm{ns}$ & $\mathrm{ns}$ & $\mathrm{ns}$ & $\mathrm{ns}$ & ns & $*$ & $\mathrm{~ns}$ & $\mathrm{~ns}$ & $\mathrm{~ns}$ \\
\hline VED vs VER & $\mathrm{ns}$ & $\mathrm{ns}$ & $\mathrm{ns}$ & ns & $\mathrm{ns}$ & * & $\mathrm{ns}$ & $*$ & $\mathrm{~ns}$ & $\mathrm{~ns}$ \\
\hline $\mathrm{AD}$ vs $\mathrm{AR}$ & $\mathrm{ns}$ & $\mathrm{ns}$ & $\mathrm{ns}$ & $\mathrm{ns}$ & $\mathrm{ns}$ & * & $\mathrm{ns}$ & * & $\mathrm{ns}$ & $\mathrm{ns}$ \\
\hline CD vs CR & $\mathrm{ns}$ & $\mathrm{ns}$ & $\mathrm{ns}$ & $\mathrm{ns}$ & $\mathrm{ns}$ & * & $\mathrm{ns}$ & * & $\mathrm{ns}$ & $\mathrm{ns}$ \\
\hline
\end{tabular}

${ }^{(1)}$ Veget. espon. (VE): vegetação espontânea. ${ }^{(2)} \mathrm{D}$ : manejo dessecado. ${ }^{(3)} \mathrm{C}$ : consórcio de trevo-branco, trevo-vermelho e azevém; ${ }^{4}$ R: manejo roçado; Ca: cálcio trocável; Mg: magnésio trocável; K: potássio; P: fósforo; CO: carbono orgânico total; L: linha; EL: entrelinha; *: significativo a $5 \%$; ns: não-significativo. Os valores da mata nativa referem-se à média das profundidades, e são acompanhados do intervalo de confiança, calculado pelo teste t. Obs: $\mathrm{Na}$ tabela, são apresentados somente os contrastes significativos.

decomposição total, incluindo-se as raízes após o manejo, o que aumentou a ciclagem de nutrientes em relação ao tratamento roçado, onde somente a parte aérea foi cortada. Além disso, o rebrote subsequente observado neste manejo pode reabsorver parte dos elementos liberados pela fitomassa decomposta. Efeito de plantas de cobertura na disponibilidade de $\mathrm{P}$ também foi observado por Silva et al. (2002), que encontraram ciclagem e incorporação de quantidades significativas de $\mathrm{P}$ ao solo em pomar de laranja-pera com cultivo intercalar de leguminosas.
O C orgânico total do solo variou de 15 a $36 \mathrm{~g} \mathrm{~kg}^{-1}$ no parreiral, enquanto na mata nativa o teor observado foi de $26 \mathrm{~g} \mathrm{~kg}^{-1}$ (Quadro 3). Na camada 0$5 \mathrm{~cm}$ do solo da entrelinha, houve interação entre manejo e cobertura, sendo observado maior teor de $\mathrm{C}$ orgânico no consórcio em relação à aveia dentro do manejo roçado. Na vegetação espontânea, o manejo dessecado resultou em maior quantidade deste atributo em relação ao roçado. Morlat \& Jacquet (2003) também observaram aumento no teor de $\mathrm{C}$ orgânico total em vinhedo do vale de Loire, na França, quando 
festuca (Festuca arundinacea Schreb) foi cultivada cobrindo $50 \%$ ou $25 \%$ da superfície do solo, comparado à eliminação completa da vegetação de cobertura com herbicida.

A produção de uva na safra colhida em 2004, após um ano de implantação do experimento, variou de 2,0 a $4,2 \mathrm{~kg}$ de uva por planta (Quadro 4), com maior produção no tratamento aveia e menor no consórcio, refletindo o efeito de planta de cobertura que teve maior produção de fitomassa na aveia em relação ao consórcio (Quadro 1). Salienta-se que o efeito benéfico do trevo, esperado em decorrência da fixação biológica de $\mathrm{N}_{2}$, não se manifestou em produtividade da videira, provavelmente porque a contribuição da matéria orgânica do solo, por meio da mineralização deste elemento foi suficiente para atender a necessidade das plantas. Destaca-se que a produtividade de uva nesta safra foi baixa em relação à média esperada na região (Mello, 2003), o que pode ter sido influenciado pelo excesso de chuva ocorrido em dezembro de 2003 (Figura 1), que provavelmente favoreceu a ocorrência de doenças, especialmente podridões-do-fruto. Já na safra 2005 , a produção variou de 5,0 a $6,2 \mathrm{~kg} /$ planta de uva, mantendo-se semelhante entre os tratamentos e sistemas de manejo que não mostraram efeito significativo. Estes valores de produção estão dentro da média de produtividade observada na região, considerando os cultivares analisados (Mello, 2003). Porém, na safra 2006, a produção foi ainda menor do que em 2004, variando de 1,5 a 3,2 kg/planta de uva, o que possivelmente decorreu da influência da condição climática no período de frutificação, em outubro, quando ocorreu excesso de chuva, que pode ter prejudicado a fecundação e o desenvolvimento inicial de frutos. Entretanto, nessa safra houve efeito de manejo na vegetação espontânea, com maior produção no tratamento dessecado em relação ao roçado (Quadro 4), o que pode ser relacionado à maior disponibilidade de nutrientes, como $\mathrm{P}, \mathrm{Ca}$ e $\mathrm{Mg}$ no solo, em virtude da maior decomposição da fitomassa dessecada, liberando esses nutrientes.
Considerando a ausência de restrições climáticas, conforme observado na safra 2005 , bem como a alta disponibilidade de nutrientes no solo do parreiral (Quadro 3), a cobertura do solo não influenciou na produtividade da uva. Entretanto, a adoção desta prática conservacionista pode contribuir na manutenção da qualidade do solo, independente da espécie ou da forma de manejo da fitomassa adotada, pela redução nas perdas por erosão e pela maior ciclagem de nutrientes. Isto ficou evidente quando observados os teores de nutrientes e C orgânico que se mantiveram estáveis com o passar do tempo (Quadro 3), embora não tenha sido aplicada qualquer adubação de reposição após a implantação do experimento.

Dal Bó \& Becker (1994) observaram que o dessecamento da cobertura de ervilhaca com herbicida, ao final do período de dormência da videira, eliminou o efeito de competição e aumentou a produtividade de frutos do cultivar Isabel em relação ao solo descoberto. Contrariamente, Faria et al. (2004), utilizando leguminosas para cobertura do solo em consorciação com videiras do cultivar Itália, não observaram efeito na produtividade e qualidade de uva comparando à testemunha, sem cobertura do solo. Rombaldi et al. (2004) também afirmam que a manutenção da cobertura do solo introduzida em março e roçada em setembro, durante as safras 2001 e 2002, em Farroupilha, RS, não afetou a produtividade e a qualidade da uva do cultivar Isabel. Da mesma forma, Ingels et al. (2005) e Wutke et al. (2005), trabalhando em condições ecológicas distintas, não observaram efeito das plantas de cobertura utilizadas nas entrelinhas do parreiral sobre a produtividade e qualidade da uva.

Dessa forma, a resposta da videira em termos de cobertura verde do solo deve ser mais estudada no que se refere à competição por água e nutrientes e também quanto aos aspectos ligados à conservação do solo, especialmente em áreas como a deste estudo, onde predominam condições de relevo acidentado e solos rasos.

Quadro 4. Produção de massa de cachos de uva fresca por planta em função de diferentes sistemas de manejo e espécies de cobertura, em três safras, num Cambissolo Háplico eutrófico, Bento Gonçalves, RS

\begin{tabular}{|c|c|c|c|}
\hline Cobertura-manejo/contrastes & 2004 & 2005 & 2006 \\
\hline & \multicolumn{3}{|c|}{ - kg/planta } \\
\hline Vegetação espontânea (VE) dessecada (D) & 2,6 & 5,0 & 3,2 \\
\hline Aveia-preta (A) dessecada & 4,2 & 6,2 & 2,6 \\
\hline Consórcio $^{(1)}$ (C) dessecado & 3,0 & 6,2 & 2,5 \\
\hline Vegetação espontânea (VE) roçada (R) & 3,0 & 5,3 & 1,5 \\
\hline Aveia-preta roçada & 3,8 & 5,2 & 2,3 \\
\hline Consórcio roçado & 2,0 & 5,5 & 2,4 \\
\hline $\mathrm{A}$ vs $\mathrm{C}$ & * & ns & $\mathrm{ns}$ \\
\hline VER vs VED & $\mathrm{ns}$ & $\mathrm{ns}$ & $*$ \\
\hline
\end{tabular}

(1) Consórcio trevo-branco, trevo-vermelho e azevém. *: significativo a $5 \%$; ns: não-significativo. Produção de uva: média das duas variedades (Niágara Branca e Niágara Rosada). 


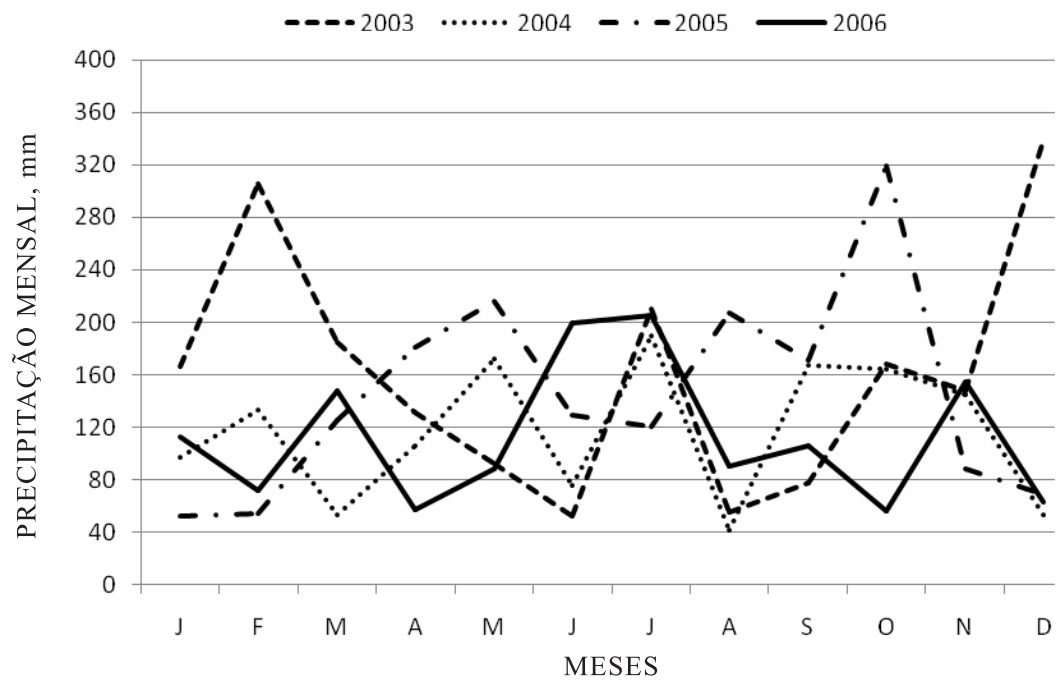

Figura 1. Precipitação média mensal (mm) em 2003, 2004, 2005 e 2006, na estação Agroclimática da Embrapa Uva e Vinho em Bento Gonçalves, RS. Fonte: Embrapa Uva e Vinho (2007).

\section{CONCLUSÕES}

1. A acidez e a disponibilidade de nutrientes no solo foram influenciadas pelas espécies de cobertura associadas à videira.

2. A dessecação das plantas de cobertura aumentou os teores de $\mathrm{Ca}^{2+}, \mathrm{Mg}^{2+}, \mathrm{P}$ e $\mathrm{C}$ orgânico no solo em relação ao manejo roçado.

3. A produtividade de uva nas safras de 2004 e 2006 foi reduzida possivelmente por restrições climáticas, sendo superior na cobertura com aveia em relação ao consórcio de espécies.

\section{LITERATURA CITADA}

BATTANY, M.C. \& GRISMER, M.E. Rainfall runoff and erosion in Napa valley vineyards: Effects of slope, cover and surface roughness. Hydrol. Process., 14:1289-1304, 2000.

COMISSÃO DE FERTILIDADE DO SOLO - CFSRS/SC Recomendação de adubação e calagem para os estados do Rio Grande do Sul e de Santa Catarina. 2.ed. Passo Fundo, Sociedade Brasileira de Ciência do Solo/Núcleo Regional Sul/ Embrapa-CNPT, 1989. 128p.

ação de sistemas de manejo para a cultura da uva. Pesq. Agropec. Bras., 29:263-266, 1994

EMBRAPA UVA E VINHO. Dados meteorológicos mensais. Disponível em: <http://www.cnpuv.embrapa.br/ meteorologia/bento-mensais.html $>$. Acesso em 15 de set. 2007.

FALCADE, I. \& MANDELLI, F. Vale dos Vinhedos: Caracterização geográfica da região. Caxias do Sul, Universidade de Caxias do Sul, 1999. 144p.

FARIA, C.M.B.; SOARES, J.M. \& LEÃO, P.C.S. Adubação verde com leguminosas no Submédio São Francisco. R. Bras. Ci. Solo, 28:641-648, 2004
GIOVANNINI, D.; MERLI, M. \& MARANGONI B. Gestione integrata e convenzionale del pescheto: Influenza sulle caratteristiche vegeto-produttive degli alberi e sulla fertilità del terreno. R. Frut.Ortoflor., 65:39-48, 2003.

INGELS, C.A.; SCOW, K.M.; WHISSON, D.A. \& DRENOVSKY, R.E. Effects of cover crops on grapevines, yield, juice composition, soil microbial ecology, and gopher activity. Am. J. Enol. Vitic., 56:19-29, 2005.

KLIK, A.; ROSNER, J. \& LOISKANDL, W. Effects of temporary and permanent soil cover on grape yield and soil chemical and physical properties. J. Soil Water Conser., 53:249-253, 1998

LOUW, P.J.E. \& BENNIE, A.T.P. Water runoff and soil erosion in vineyard soil. Australian Grapegrower Winemaker, 349:110-113, 1992.

MELLO, L.M.R. Uvas americanas e híbridas para processamento em clima temperado. Bento Gonçalves, Embrapa Uva e Vinho, 2003. (Sistemas de Produção, 2)

MORLAT R. \& JACQUET A. Grapevine root system and soil characteristics in a vineyard maintained long-term with or without interrow sward. Am. J. Enol. Vitic., 54:1-7, 2003.

OLIVEIRA, O.L.P.; JUERGEN, J.P.; BELLÉ, V. \& RIGO, J.C. Manejo do solo e da cobertura verde em videiras visando sustentabilidade. Bento Gonçalves, Embrapa Uva e Vinho - CNPUV, 2004. 4p. (Comunicado Técnico, 55)

OLIVEIRA O.L.P.; PICCININI C.S.; PALUDO M.B. \& JUERGEN J.P. Manejo da cobertura do solo em videiras visando à sustentabilidade do ecossistema: Relação das espécies de cobertura com as videiras e com a produção e qualidade da uva. R. Bras. Agroec., 2:1198-1201, 2007.

POCKNEE, S. \& SUMNER, M.E. Cation and nitrogen contents of organic matter determine its soil liming potential. Soil Sci. Soc. Am. J., 61:86-92, 1997. 
PROTAS, J.F.S. Programa de desenvolvimento estratégico da vitivinicultura do Rio Grande do Sul - Visão 2005. In: CONGRESSO LATINO AMERICANO DE VITICULTURA E ENOLOGIA, 10., Bento Gonçalves, 2005. Anais. Bento Gonçalves, Embrapa Uva e Vinho, 2005. p.109-130. (Documentos, 55)

ROMBALDI, C.V.; BERGAMASQUI, M.; LUCCHETTA, L.; ZANUZO, M. \& SILVA, J.A. Produtividade e qualidade de uva, cv. Isabel, em dois sistemas de produção. R. Bras. Frutic., 26:89-91, 2004.

RUFATO, L.; RUFATO, A.R.; KRETZSCHMAR, A.A.; PICOLOTTO, L. \& FACHINELLO, J.C. Coberturas vegetais no desenvolvimento vegetativo de plantas de pessegueiro. R. Bras. Frutic., 29:107-109, 2007.

SILVA, J.A.A.; VITTI, G.C.; STUCHI, E.S. \& SEMPIONATO, O.R. Reciclagem e incorporação de nutrientes ao solo pelo cultivo intercalar de adubos verdes em pomar de Laranjeira-'Pêra'. R. Bras. Frutic., 24:225-230, 2002.
TEDESCO, M.J.; GIANELLO, C.; BISSANI, C.A.; BOHNEN, H. \& VOLKWEISS, S.J. Análises de solo, plantas e outros materiais. 2.ed. Porto Alegre, Universidade Federal do Rio Grande do Sul, 1995. 174p. (Boletim Técnico de Solos, 5)

TESIC, D.; KELLER, M. \& HUTTON, R.J. Influence of vineyard floor management practices on grapevine vegetative growth, yield, and fruit composition. Am. J. Enol. Vitic., 58:1-11, 2007.

WUTKE, E.B.; CARVALHO, C.R.L.; COSTA, F.; TERRA, M.; PIRES, E.J.P.; SECCO, I. L. \& RIBEIRO, I.J.A. Qualidade de frutos de videira 'Niagara Rosada' em cultivo intercalar com gramíneas e leguminosas. R. Bras. Frutic., 26:92-96, 2004 .

WUTKE, E.B.; CARVALHO, C.R.L.; COSTA, F.; TERRA, M.; PIRES, E.J.P.; SECCO, I.L. \& RIBEIRO, I.J.A. Influência da cobertura vegetal do solo na qualidade de frutos de videira 'Niagara Rosada'. R. Bras. Frutic., 27:434-439, 2005. 